\title{
The effect of curing and zirconium content on the wettability and structure of a silicate hybrid sol-gel material
}

\author{
Emma MacHugh \\ Technological University Dublin \\ Maikki Cullen \\ Technological University Dublin \\ Alicja Kaworek \\ Technological University Dublin
}

See next page for additional authors

Follow this and additional works at: https://arrow.tudublin.ie/scschcpsart

Part of the Chemical Engineering Commons, Chemistry Commons, Engineering Science and Materials Commons, and the Materials Science and Engineering Commons

\section{Recommended Citation}

Emma MacHugh, Maikki Cullen, Alicja Kaworek, Brendan Duffy, Mohamed Oubaha, The effect of curing and zirconium content on the wettability and structure of a silicate hybrid sol-gel material, Journal of NonCrystalline Solids, Volume 525, 2019, 119658, ISSN 0022-3093, DOI: 10.1016/j.jnoncrysol.2019.119658.

This Article is brought to you for free and open access by the School of Chemical and Pharmaceutical Sciences at ARROW@TU Dublin. It has been accepted for inclusion in Articles by an authorized administrator of ARROW@TU Dublin. For more information, please contact arrow.admin@tudublin.ie, aisling.coyne@tudublin.ie, gerard.connolly@tudublin.ie.

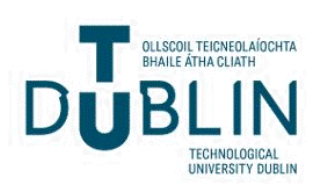




\section{Authors}

Emma MacHugh, Maikki Cullen, Alicja Kaworek, Brendan Duffy, and Mohamed Oubaha

This article is available at ARROW@TU Dublin: https://arrow.tudublin.ie/scschcpsart/115 


\title{
The effect of curing and zirconium content on the wettability and structure of a silicate hybrid sol-gel material
}

\author{
Emma MacHugh $^{\mathrm{a}, \mathrm{b}}$, Maikki Cullen ${ }^{\mathrm{a}, \mathrm{b}}$, Alicja Kaworek ${ }^{\mathrm{b}}$, Brendan Duffy ${ }^{\mathrm{b}}$, Mohamed Oubaha ${ }^{\mathrm{b}, *}$ \\ ${ }^{a}$ School of Chemical and Pharmaceutical Sciences, Technological University Dublin, Kevin Street, Dublin 8, Ireland \\ ${ }^{\mathrm{b}}$ Centre for Research in Engineering Surface Technology (CREST), FOCAS Institute, Technological University Dublin, 13 Camden Row, Dublin 8, Ireland
}

\section{A R T I C L E I N F O}

\section{Keywords:}

Sol-gel

Coatings

Structure

Condensation

Hybrid

\begin{abstract}
A B S T R A C T
Functional hybrid sol-gel coatings have been developed for numerous applications with a wide range of wettabilities. This study proposes to investigate the relationship between the structure and the wetting properties of a zirconium modified silicate hybrid sol-gel coating. The structures of the coatings were altered by varying the content of zirconium, and the curing process, while keeping the sol-gel preparation conditions identical. The structure of the materials was characterized by FTIR, ${ }^{29} \mathrm{Si}$ NMR and SEM. The thermal properties and the wettability are identified by DSC and contact angle measurements, respectively.

By corroborating the structural and wettability analyses, it is shown that the transition metal minimizes the thermally-assisted condensation of the silicate network and enables to stabilize the wetting properties at higher hydrophilic values. This article highlights that the wettability of hybrid sol-gel coatings can be controlled by both the curing process and transition metal content.
\end{abstract}

\section{Introduction}

Control of coatings wettability is of great interest for a wide range of applications; including sensors for medical and environmental monitoring, protective coatings for transportation and construction industries among others. One of the key issues with the development of highly sensitive sensor devices is the functionalization of sensing surfaces with recognition probes that enable specific binding with biological or chemical analytes, thus requiring sensing surfaces with controlled wettability [1]. Microfluidics are widely used in medical and environmental monitoring devices and their fluidic efficiency depends on their surface energy [2]. Protective coatings for anticorrosion, antifouling or antibacterial purposes often need low surface energies to minimize interactions between the protected surface and contaminant fluids [3]. High surface energy surfaces are essential for adhesion of organic coatings to enable the formation of homogenous and highly adherent coatings [4].

Over the past three decades, hybrid sol-gel materials have been widely investigated for the fabrication of functional coatings [5]. The dual organic and inorganic character of the precursors coupled to the liquid nature of the sol-gel process have been particularly attractive to the preparation of newly hierarchically structured materials with wettability ranging from (super)hydrophobic [6] to (super)hydrophilic $[7,8]$. However, to our knowledge, no research has precisely focused on the influence of the curing and structure of the hybrid sol-gel material on the wettability of hybrid organic-inorganic sol-gel coatings. This study is aimed at providing initial responses to these fundamental questions by studying an established hybrid sol-gel material prepared from the combination of a silicate and zirconium hybrid precursors previously reported on by us [9]. While previous studies completed by us focused on the structure of the hybrid sol-gel coatings towards anticorrosion applications, this study centres on the effect of the curing on the structure and wettability of hybrid sol-gel coatings. To better understand the effect of the structure on the wetting properties of the coatings, the relative content of the silicon and zirconium precursors was altered while keeping the sol-gel synthesis and coatings fabrication conditions identical. The properties of the hybrid sol-gel materials were characterized employing Fourier transform infrared spectroscopy (FTIR), silicon nuclear resonance spectroscopy $\left({ }^{29} \mathrm{Si} N \mathrm{NM}\right)$ and scanning electron microscopy (SEM). The wettability was identified by contact angle measurements. The thermal properties were characterized by differential scanning calorimetry (DSC).

\section{Experimental section}

\subsection{Sol gel synthesis}

Five hybrid sol-gel materials were prepared from the combination of

\footnotetext{
* Corresponding author.

E-mail address: mohamed.oubaha@dit.ie (M. Oubaha).
} 
Table 1

Materials formulation.

\begin{tabular}{lll}
\hline Materials & $\begin{array}{l}\text { Theoretical hydrolysis degree (vs. alkoxide } \\
\text { groups) }\end{array}$ & MAPTMS:ZPO:MAAH \\
\hline A & $50 \%$ & $99: 1: 1$ \\
B & $50 \%$ & $95: 5: 5$ \\
C & $50 \%$ & $90: 10: 10$ \\
D & $50 \%$ & $80: 20: 20$ \\
E & $50 \%$ & $70: 30: 30$ \\
\hline
\end{tabular}

two hybrid precursors in different relative ratios (Table 1): (1) an organically modified silicate precursor, 3-(trimethoxysilyl)propyl methacrylate (MAPTMS, Assay 99\% in methanol) and a zirconium complex, prepared from the chelation of zirconium n-propoxide (ZPO, Assay 70\% in 2-propanol) with methacrylic acid (MAAH, Assay >98\%). The solgel synthesis necessitates a three-step process to enable the formation of a fully stable nano-hybrid system where zirconium species are homogeneously distributed within the hybrid silicate matrix, as fully described in our previous study [9].

\subsection{Fabrication of the sol-gel coatings}

The five prepared sols were filtered using a $0.45 \mu \mathrm{m}$ nylon syringe filter and deposited onto glass substrates by spin coating at $1000 \mathrm{rpm}$. The glass substrates were cleaned with isopropanol prior to deposition. From each sol, five coatings were prepared and each one underwent a different curing temperature $\left(100,120,130,140\right.$ and $\left.150{ }^{\circ} \mathrm{C}\right)$ for a duration of $1 \mathrm{~h}$, resulting in a set of 25 samples. The process was repeated five times for reproducibility testing.

\subsection{Contact angle measurements}

Water contact angles (CA) were measured using the static sessile drop method on the hybrid sol-gel coatings. The measurements were taken using deionized water under ambient conditions using an electronic syringe. The CA measurements were recorded using a contact angle goniometer-FTA200 First Ten Angstroms. Uniform droplets of 4.1 $\mu \mathrm{l}$ of deionized water were dropped onto the surface of the coatings and allowed to stabilize for $10 \mathrm{~s}$ before digital images of the droplets were recorded. For statistical analyses, five coatings for each material were prepared with six measurements taken for each coating, leading to 30 values. The contact angle values were determined from the average of the 30 measurements and the uncertainty values determined from the minimum and maximum values of these 30 measurements. The images were then analysed using FTA32 Video 2.0 software.

\subsection{Fourier transform infrared spectroscopy (FT-IR)}

FT-IR was employed to highlight the different vibrational modes of the chemical species within the sol-gel coatings, particularly to follow the evolution of the silicate network when the curing temperature and zirconium content are altered. The FT-IR spectra of all coatings were obtained using a Perkin Elmer GX instrument in the ATR mode within a $650-4000 \mathrm{~cm}^{-1}$ spectral range.

\subsection{Silicon nuclear magnetic spectroscopy $\left({ }^{29} \mathrm{Si} N \mathrm{NMR}\right)$}

${ }^{29} \mathrm{Si}$-NMR experiments were carried out for the sols $24 \mathrm{~h}$ after their synthesis. The main information of interest was the evolution of the condensation degree of the silicon atoms as a function of zirconium concentration. The experiments were run employing a $400 \mathrm{MHz}$ Bruker spectrometer equipped with an INEP pulse sequence. The acquisition conditions are as follows: frequency $46.69 \mathrm{MHz}$, spectral width $500 \mathrm{ppm}$, pulse $\pi / 3(8 \mu \mathrm{s})$, recycle delay $4 \mathrm{~s}$, number of scans 80 and the free induction delay (FID) fixed at $10 \mathrm{~Hz}$ line broadening. Deuterated dimethylsulfoxide (DMSO) was used as a lock solvent and tetramethylsilane (TMS) - as a chemical shift reference. For the statistical analyses of the content of the $\mathrm{T}$ species, each material was prepared three times and NMR spectra recorded three times, leading to nine measurements per material. The value of the $\mathrm{T}$ species was determined by the average of the obtained nine measurements and the uncertainty values defined from the minimum and maximum values of the nine measurements.

\subsection{Differential scanning calorimetry (DSC)}

DSC was employed to look at the thermal stability and reactivity of the sols over the temperature range of $25-300^{\circ} \mathrm{C}$. The measurements were carried out using a Shimadzu DSC QC instrument under an air atmosphere and a heating rate of $5{ }^{\circ} \mathrm{C} / \mathrm{min}$.

\subsection{Scanning electron microscopy (SEM)}

SEM experiments were performed on the cross-section of the coatings to identify their thickness, homogeneity and adhesion on the glass substrate.

The SEM images were recorded employing a Hitachi SU-70 SEM with electron energy of $2-10 \mathrm{keV}$. Prior to analysis, the samples were sputter coated with a palladium layer of approximately $6 \mathrm{~nm}$ in thickness using a Cressington 208HR sputter coater.

\section{Results and discussion}

\subsection{Contact angle measurements}

The contact angle (CA) measurement of all materials were performed and the average contact angles plotted as a function of temperature are shown in Fig. 1 . At $100{ }^{\circ} \mathrm{C}$, materials containing 1 to $20 \%$ ZPO exhibit a CA close to $67^{\circ}$, whereas the material containing $30 \%$ ZPO has a slightly higher CA value of $71^{\circ}$. As the temperature increases to a $120^{\circ} \mathrm{C}$ it can be seen that the opposite tendency is observed with samples containing a high content of ZPO exhibiting lower CA values than those with a lower ZPO content. Interestingly, except for material A, all other materials show a stagnation of their CA value from a curing temperature of $130^{\circ} \mathrm{C}$. Unlike the other materials, material A shows an increase of the CA from 130 to $150{ }^{\circ} \mathrm{C}$. These observations clearly signify that the zirconium content plays a role in the surface properties of the materials. The hypothesis to explain this behaviour can be related to the formation of hydrophilic species at temperatures up to $130^{\circ} \mathrm{C}$ with a partial conversion of the hydrophilic species into hydrophobic groups. However, this variation can only be possible if the morphology of the materials is dramatically different from low to high ZPO concentrations, therefore favouring the conversion of hydrophilic species to hydrophobic species at low ZPO concentrations. In other words, this

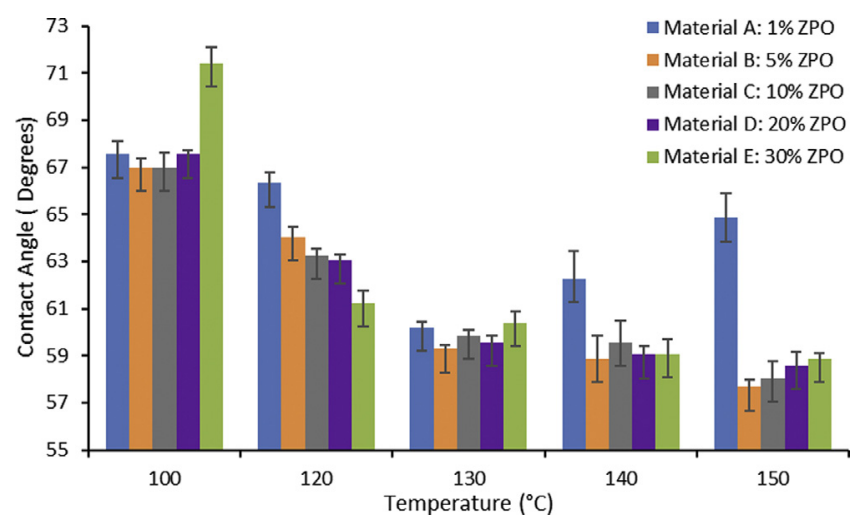

Fig. 1. CA measurements vs temperature for all materials. 


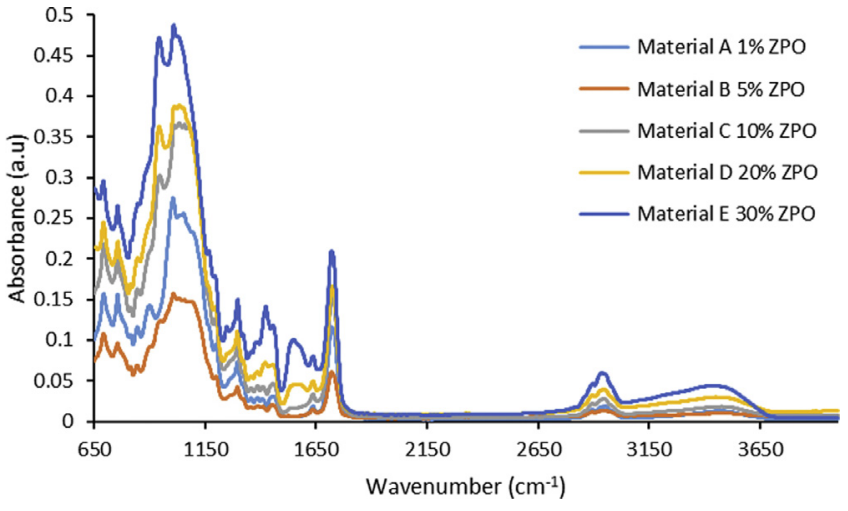

Fig. 2. FT-IR spectra of materials A-E in the range of $650-4000 \mathrm{~cm}^{-1}$.

phenomenon would be possible if material A exhibits a higher porosity than other materials, therefore having the ability to be hydrophilized at temperatures lower than $130{ }^{\circ} \mathrm{C}$ and hydrophobized at higher temperatures. This would mean that the surface properties would be governed by a competition between a hydrophilization process at low temperatures and a hydrophobization process taking place at higher temperatures, likely due to the conversion of hydroxyl groups into oxide groups. In order to confirm or disconfirm this hypothesis, FT-IR analyses of the evolution of the inorganic groups are required.

\subsection{FT-IR}

The recorded FT-IR spectra for all materials were found to exhibit similar chemical vibrations, as shown in Fig. 2 (samples cured at $100^{\circ} \mathrm{C}$ ). This is due to the formation of the same chemical groups because of a uniform preparation process, the only difference being the MAPTMS/ZPO ratio. To identify the effects of the curing temperature and material formulations on the reactivity and condensation of the inorganic network, it is important to focus on the characteristic absorption bands of the inorganic backbone of the materials. For this reason, the absorption bands in the range $800-1250 \mathrm{~cm}^{-1}$ were investigated, as shown in Fig. 3. In the previous study [9], it was found that, for a curing temperature of $120^{\circ} \mathrm{C}$, the ZPO content significantly affects the absorption in the $800-1250 \mathrm{~cm}^{-1}$ range, but here the effect of the curing temperature is investigated in the domain of temperatures usually required for fully stabilizing hybrid sol-gel coatings, from 100 to $150^{\circ} \mathrm{C}$. The absorption bands were attributed according to the results of previous studies [10-15]. For material A, it can be observed that the $\mathrm{Si}-\mathrm{O}-\mathrm{Si}$ symmetric stretching band located at $815 \mathrm{~cm}^{-1}$ and the $\mathrm{Si}-\mathrm{O}-\mathrm{C}$ symmetric stretching bands located at 1170 and $1200 \mathrm{~cm}^{-1}$ decrease when the curing temperature increases. In parallel, the broad band located in the range $1000-1100 \mathrm{~cm}^{-1}$ and related to the asymmetric stretching of the $\mathrm{Si}-\mathrm{O}-\mathrm{Si}$ bonds is seen to shrink from the high energy vibrations as the curing temperature increases. Actually, this band is composed itself by the superimposition of five sub-bands located at 1010, 1030, 1055, 1070 and $1090 \mathrm{~cm}^{-1}$. According to Lerot and Low [16], the band located at $1090 \mathrm{~cm}^{-1}$ is attributed to siloxane units located at the interface between tetrahedral and octahedral units, whereas the lower energy bands would relate to siloxane units at the interface between tetrahedral units. From this reference, one can suppose that in our system, in this spectral region, the high-energy vibrations would represent the siloxane bonds with a more structured network whereas the lower ones would be related to a more disordered network. Therefore, the decrease of the intensities of the bands with higher energy indicates the formation of a network with a lower connectivity, probably with a higher porous morphology. This hypothesis is supported by the intensity decrease of the symmetric stretching of the $\mathrm{Si}-\mathrm{O}-\mathrm{Zr}$ bond located at $940 \mathrm{~cm}^{-1}$. Finally, although the intensity of the band related to the symmetric vibration of the $\mathrm{Si}-\mathrm{OH}$ group located at $890 \mathrm{~cm}^{-1}$ is seen to decrease, its relative intensity against the $\mathrm{Si}-\mathrm{O}-\mathrm{Si}$ groups ( 815 and $1000-1150 \mathrm{~cm}^{-1}$ ) is found to be the highest for the sample cured at $130^{\circ} \mathrm{C}$. This supports the CA measurements where the sample cured at $130^{\circ} \mathrm{C}$ was found to be the most hydrophilic sample for material A. In summary, for material A, the increase of the curing temperature provokes the formation of hydrophilic silanol groups at up to $130^{\circ} \mathrm{C}$. The higher curing temperatures tend to form hydrophobic siloxane groups with increasing amorphous character of the inorganic network.

For materials $\mathrm{B}$ to $\mathrm{E}$, the bands related to the symmetric siloxane $\left(815 \mathrm{~cm}^{-1}\right)$ and residual alkoxysilane $\left(1175 \mathrm{~cm}^{-1}\right)$ groups are seen to decrease as the curing temperature increases. The relative intensity of the silanol $\left(840 \mathrm{~cm}^{-1}\right)$ groups against the symmetric siloxane stretching increases as the concentration of the zirconium precursor increases, suggesting that the zirconium atom favours the formation of hydrophilic $\mathrm{Si}-\mathrm{OH}$ groups. The shrinkage of the asymmetric siloxane vibrations bands $\left(1000-1150 \mathrm{~cm}^{-1}\right)$, which was identified for material $\mathrm{A}$, is not observed for materials B to D and the opposite effect is observed for material E. The progressive increase of the zirconium content minimizes the decrease of the $\mathrm{Si}-\mathrm{O}-\mathrm{Zr}$ band located at $940 \mathrm{~cm}^{-1}$, suggesting the formation of more stable structures. Therefore, one can conclude that the zirconium precursor favours the formation of highly condensed silicate species, resulting in a more condensed network. Finally, these results indicate that the incorporation of the transition metal favours the formation of denser materials, thus limiting the further condensation process observed in material $\mathrm{A}$, and the subsequent contact angle increase. However, to better identify the effect of the zirconium incorporation on the morphology of the silicate network and its subsequent consequences on the wetting capabilities of the coatings, we propose to perform ${ }^{29} \mathrm{Si}$ NMR analyses of the materials investigated here. Importantly, this would enable us to confirm or disconfirm the competition between the hydroxylation and condensation processes discussed in this section.

\section{3. ${ }^{29} \mathrm{Si} N M R$}

The ${ }^{29} \mathrm{Si}$ NMR spectra were recorded for all materials $24 \mathrm{~h}$ after fabrication and they are shown in Fig. 4. The spectrum of the precursor MAPTMS was also recorded and is represented in Fig. 5. The presence of a single sharp peak at $-42.6 \mathrm{ppm}$ demonstrates the absence of hydrolysed or condensed species and its high purity. The presence of the different chemical shifts in the $T_{0}, T_{1}, T_{2}$ and $T_{3}$ regions of the spectra correspond to the different degrees of condensation of the silicon atoms in MAPTMS and it was previously reported [9]. Firstly, it can be noted that no $T_{0}$ species are observed for any material, suggesting that all silicon atoms have formed at least one siloxane bond. However, this does not mean that all alkoxide group have reacted, as each silicon atom within MAPTMS contains 3 reactive alkoxide groups. To better appreciate the evolution of the different $\mathrm{T}$ species for each material, the different chemical shifts have been integrated and their relative proportions are plotted in Fig. $6 . \mathrm{T}_{1}$ species are present in all materials A-E at ratios of $32.2,4.8,2.7,3.5$ and $13.3 \%$, respectively. $\mathrm{T}_{2}$ species are present at a ratio of $50,50.3,45.2,42.4$, and $44.2 \%$, respectively. The most condensed species $\mathrm{T}_{3}$ is present in concentrations of $17.1,44.8$, 52,54 , and $42.4 \%$, respectively. The increase of the $T_{3}$ species at the expense of both the $T_{2}$ and $T_{1}$ species suggests that the materials are forming more condensed networks with increasing zirconium concentrations up to $20 \%$. For material E, with a ZPO concentration of $30 \%$, there is a dramatic increase in the concentration of $\mathrm{T}_{1}$ species with a decrease in the $\mathrm{T}_{3}$ species.

In summary, the ${ }^{29} \mathrm{Si}$ NMR analyses suggests the zirconium precursor favours the formation of a more condensed silicate species at concentrations up to $20 \%$. At a concentration of $30 \%$, the lower condensed $\mathrm{T}_{1}$ silicate species are formed minimizing further condensation probably due to the steric hindrance caused by the large size of the zirconium atom. Importantly, these results confirm that the silicate 

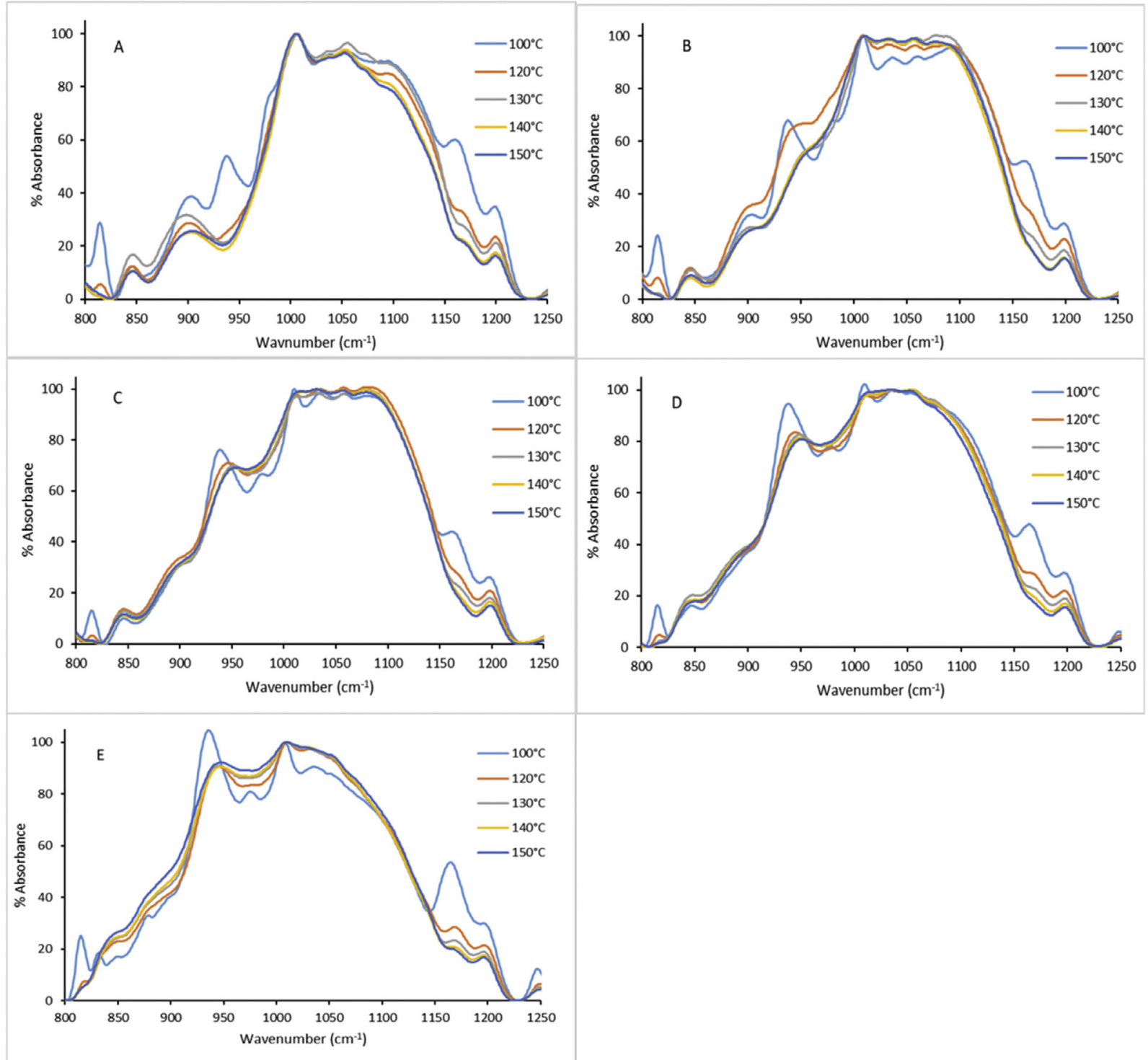

Fig. 3. FT-IR spectra of materials A-E in the range of $800-1250 \mathrm{~cm}^{-1}$.

network is less sensitive to condensation reactions as the zirconium content increases and to subsequent contact angle increase, as demonstrated above by the CA and FT-IR analyses.

\subsection{Thermal analysis}

The DSC measurements were performed on all the liquid sol-gel materials to determine their thermal behaviour and to identify the optimum working temperature of the sol-gel material. The thermal behaviour of materials A-E are given in Fig. 7. There are three different areas of thermal behaviour that can be observed, namely, between 25 and $70{ }^{\circ} \mathrm{C}, 100$ and $170{ }^{\circ} \mathrm{C}$ and above $170{ }^{\circ} \mathrm{C}$. The large broad endothermic band between 25 and $70{ }^{\circ} \mathrm{C}$ is due to the evaporation of free volatile solvents within the hybrid network formed during the sol-gel synthesis and contained in the precursors. The endothermic band shifts to higher temperatures with increasing zirconium content; this may be due to a higher degree of entrapped solvents in the sol-gel network. Similar behaviour has been reported for $\mathrm{Sn}$ doped $\mathrm{ZrO}_{2}$ samples which were prepared by sol-gel methods [17]. The exothermic band between 160 and $190^{\circ} \mathrm{C}$ is due to the glass transition phase (Tg) or the full solidification point of the sol-gel materials. It can be noted that the $\mathrm{Tg}$ for materials B to E can be seen at 194, 194, 185 and $199^{\circ} \mathrm{C}$, respectively.
Material A, exhibits two exothermic bands in the region of 171 and $192^{\circ} \mathrm{C}$, which may be due to the occurrence of two different phases within the material due to the low content of ZPO, as previously observed in similar materials [9]. Apart from materials C and D, an additional exothermic band located above $200{ }^{\circ} \mathrm{C}$ is present for the other materials, translating structural heterogeneity, probably due to the presence of hybrid nanoparticle populations with different structures, thus with different thermal behaviors. The most plausible explanation to the likely heterogeneity can be explained by the capability of the silicate network to host the zirconium complex in a homogeneous manner within its backbone. At low zirconium concentrations (materials $\mathrm{A}$ and $\mathrm{B}$ ), the sol-gel network may be primarily composed of silicate species with some local inclusions of zirconium species. At the highest zirconium content (material E), the silicate network may not be able to host the whole content of zirconium species, thus leading to some rich zirconium nanoparticles populations. According to this explanation, the integration of the zirconium complex in the silicate network is optimum in materials C and D. However, to clarify this question further fine structural characterizations at the different curing temperatures employing XRD, EXAFS, XANES or neutron scattering are needed, which we expect to address in a future study. 


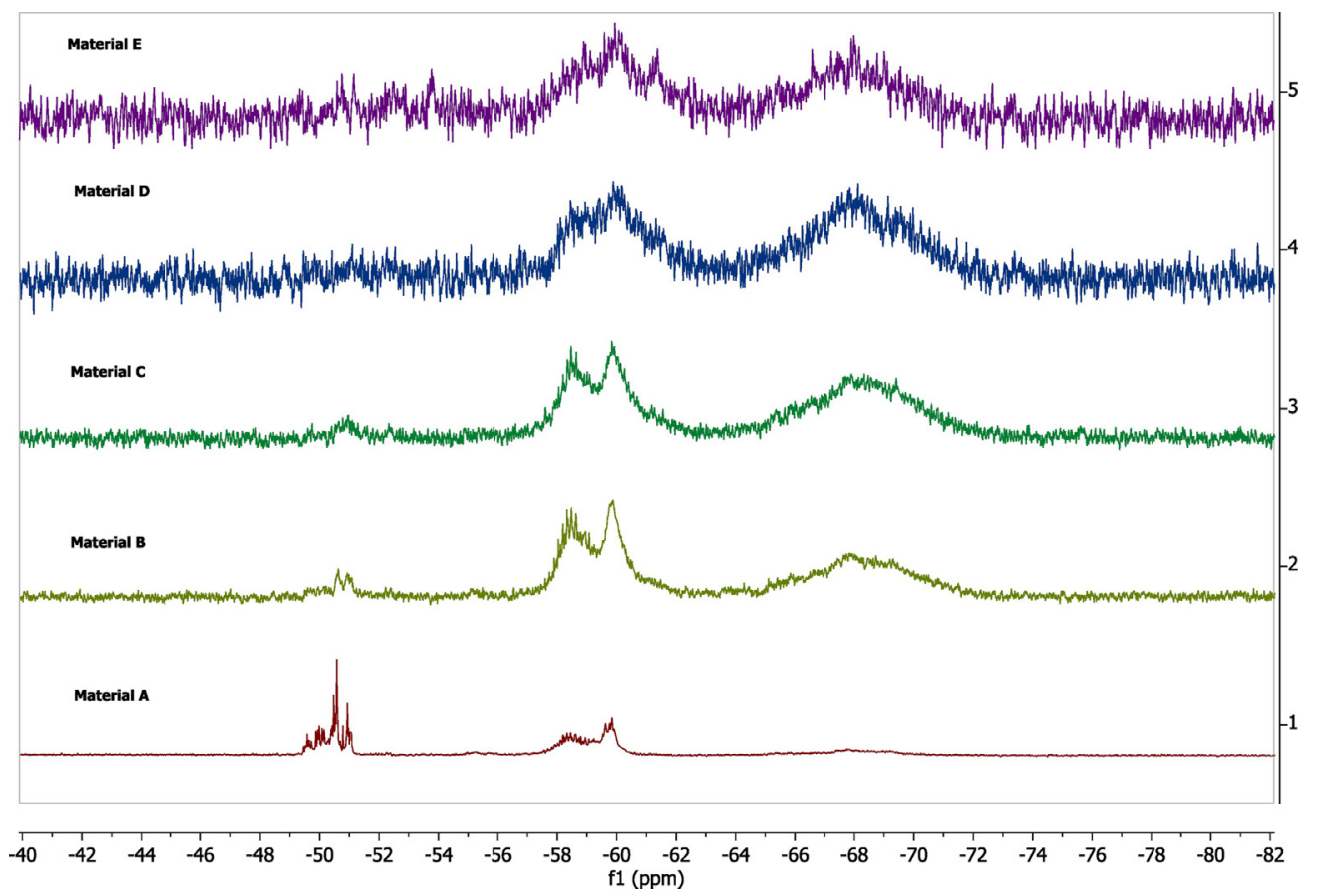

Fig. $4 .{ }^{29} \mathrm{Si} \mathrm{NMR} \mathrm{spectra} \mathrm{of} \mathrm{all} \mathrm{materials.}$

\subsection{SEM analysis}

The SEM images of cross-sectioned samples were recorded to identify the coating homogeneity and thicknesses, as well as adhesion on the glass substrate for all materials. All samples show homogenous coatings with thicknesses in the range of $4.8-6 \mu \mathrm{m}( \pm 0.5 \mu \mathrm{m})$, as seen in Fig. 8. Although the sample preparation involved mechanical cleaving of the substrate in order to enable cross-section analysis on a sharp interface, no delamination of the coatings from the glass substrate was observed, demonstrating a strong adhesion of the sol-gel materials with the glass substrate. As the glass substrate surface contains silanol groups, it is likely that they will undergo inorganic condensation with

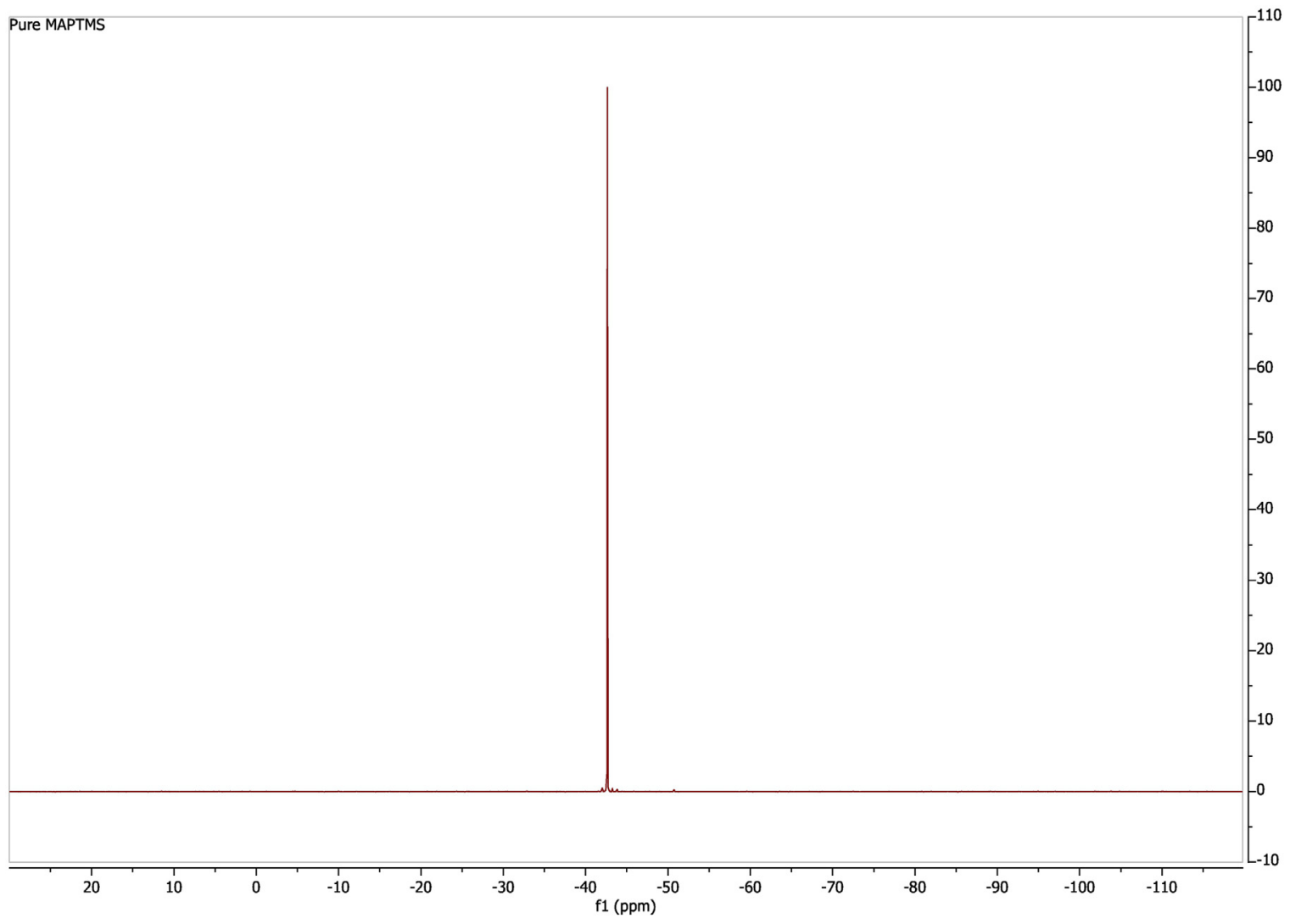

Fig. $5 .{ }^{29} \mathrm{Si}$ NMR spectra of pure MAPTMS precursor. 


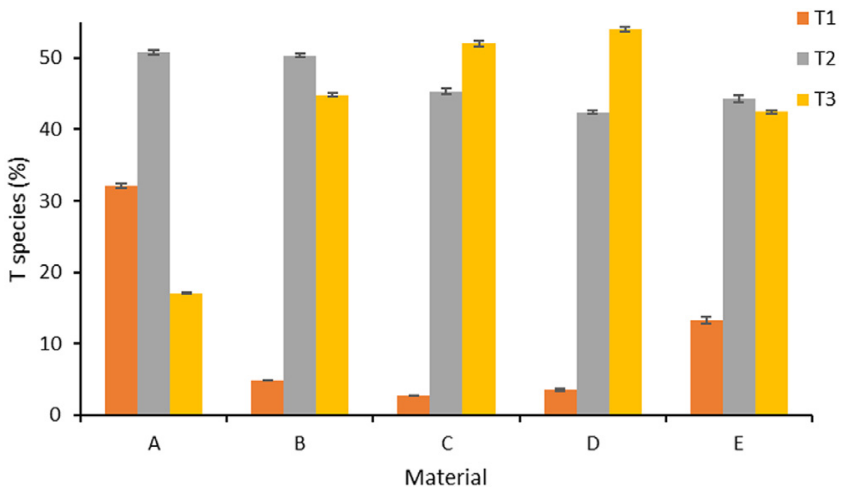

Fig. 6. Evolution of $\mathrm{T}_{1}, \mathrm{~T}_{2}$ and $\mathrm{T}_{3}$ species for all materials.

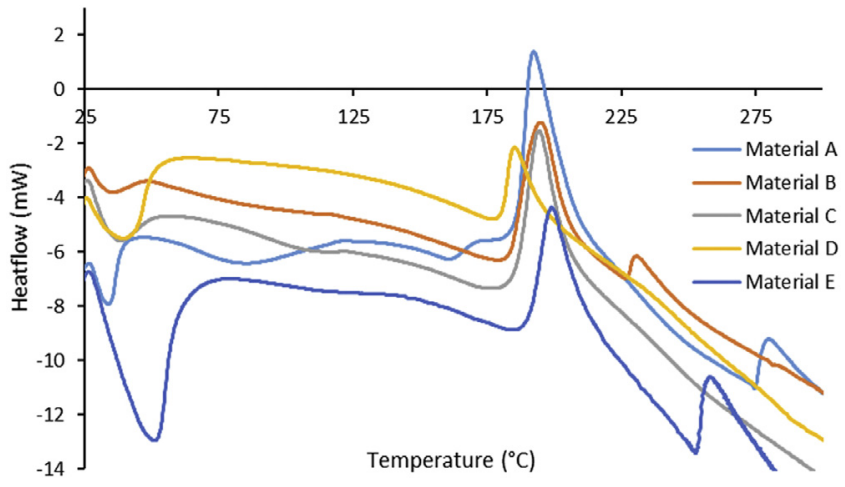

Fig. 7. DSC spectra of all materials.

the residual uncondensed silanol and alkoxysilane groups of the sols to form strong siloxane bonds, thus explaining the strong adhesion of the hybrid sol-gel coating onto the substrate. Apart from the stripes observed on the cross-section, which are due to the propagation of the cleaving defects of the glass substrate, the coating is found to be smooth and uniformly distributed on the substrate, suggesting a highly homogeneous material.

\section{Conclusion}

The objective of this work was to investigate the relationships existing between the structure, the curing temperature and the wetting properties of a zirconium modified organosilane hybrid sol-gel material. A series of five hybrid materials were prepared from the combination of a silicon and zirconium hybrid sol-gel reactive at different ratios. The materials were structurally and thermally analysed by FT-IR, ${ }^{29} \mathrm{Si}$ NMR, SEM and DSC methods and the wetting properties clarified by CA measurements. The FT-IR analysis showed that the curing temperature provokes the condensation of the silicate network at the expense of the $\mathrm{Si}-\mathrm{O}-\mathrm{Zr}$ and $\mathrm{Si}-\mathrm{OH}$ groups. However, this phenomenon decreases as the zirconium content increases, suggesting the zirconium precursor minimizes the progression of the silicate network probably by the formation of a rigid network in the liquid phase. Indeed, ${ }^{29} \mathrm{Si} \mathrm{NMR}$ characterizations have supported this hypothesis by showing that highly condensed silicate species are formed in the liquid phase when the content of zirconium increases. From the cross-section SEM observation, the prepared coatings are found to be uniformly deposited onto the glass substrate with thicknesses ranging from 4.8 to $6 \mu \mathrm{m}$ $( \pm 0.5 \mu \mathrm{m})$. The wettability analysis showed that all coatings exhibit a progressive decrease of their CA values up to $130{ }^{\circ} \mathrm{C}$. At temperatures above $130^{\circ} \mathrm{C}$, the sample containing $1 \%$ zirconium content exhibits an increase of its CA value, while coatings containing a minimum of $5 \%$ of zirconium maintain a stable CA value. Therefore, when corroborating the structural and wettability analyses, it has become evident that the transition metal minimizes thermal condensation of the silicate network, thus enabling stabilization of the wetting properties at higher hydrophilic values.

To our knowledge, the control of the wettability of hybrid coatings by curing process and transition metal incorporation within a silicate network is a fundamentally new concept in the physico-chemistry of hybrid sol-gel materials, which would deserve to be further investigated on other structurally different materials and other curing methodologies.

\section{Declaration of Competing Interest}

The authors declare that they have no known competing financial interests or personal relationships that could have appeared to
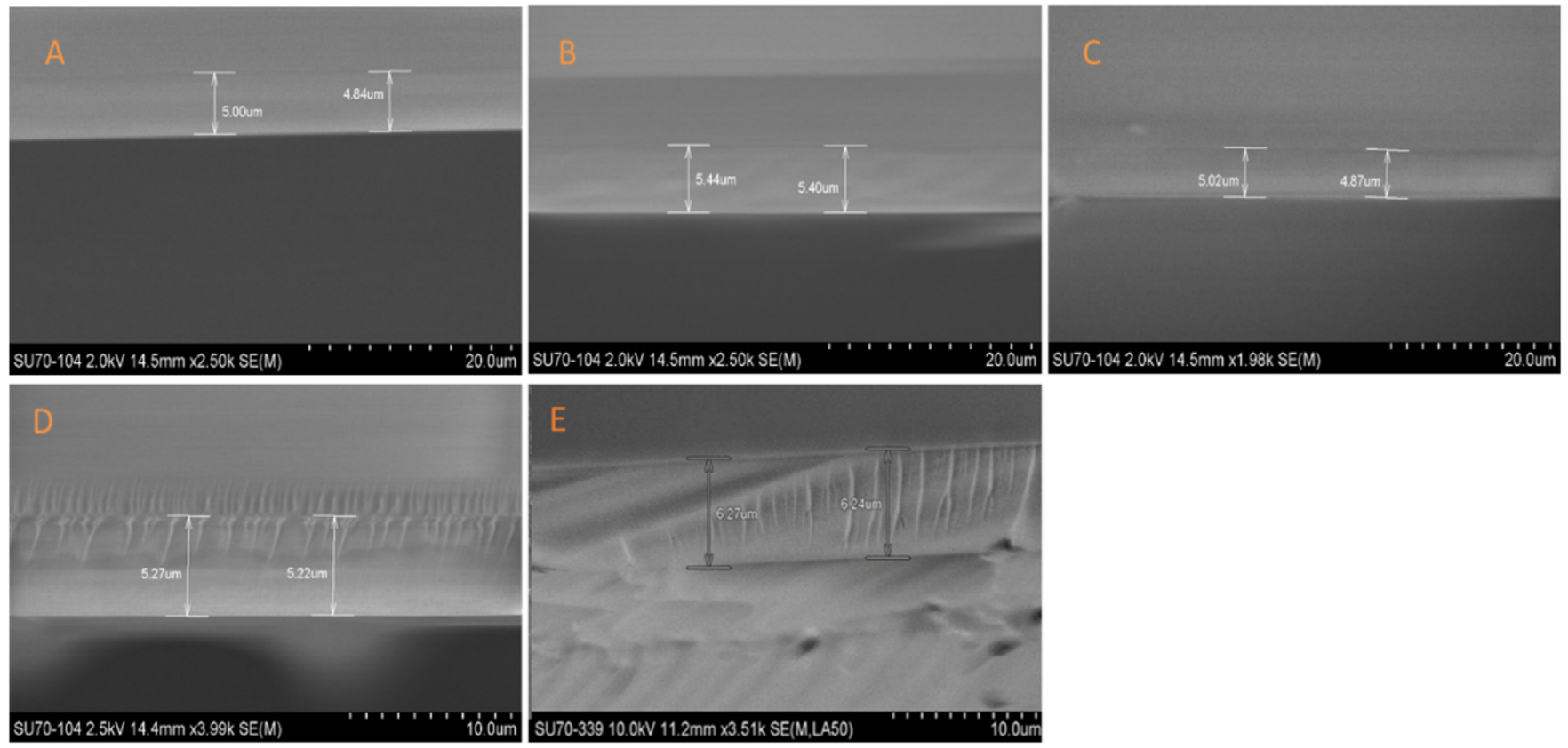

Fig. 8. SEM images of all materials A-E. 


\section{influence the work reported in this paper.}

\section{References}

[1] María-José Bañuls, Rosa Puchades, Ángel Maquieira, Chemical surface modifications for the development of silicon-based label-free integrated optical (IO) biosensors: a review, Anal. Chim. Acta 777 (2013) 1-16.

[2] Eric K. Sackmann, Anna L. Fulton, David J. Beebe, The present and future role of microfluidics in biomedical research, Nature 507 (2014) 181-189.

[3] Bo Liu, Kaiqiang Zhang, Chao Tao, Yunhui Zhao, Xiaohui Li, Kongying Zhu, Xiaoyan Yuan, Strategies for anti-icing: low surface energy or liquid-infused? RSC Adv. 6 (2016) 70251-70260.

[4] Jaroslaw Drelich, Emil Chibowski, Dennis Desheng Meng, Konrad Terpilowski, Hydrophilic and superhydrophilic surfaces and materials, Soft Matter 7 (2011) 9804-9828.

[5] Mohamed Oubaha, Sol-Gel Strategies for Hybrid Materials, World Scientific Reference of Hybrid Materials, Volume 3 World Scientific, January 2019 To be published.

[6] S. Czyzyk, A. Dotan, H. Dodiuk, S. Kenig, Easy-to-clean superhydrophobic coatings based on sol-gel technology: a critical review, Rev. Adhesion Adhesives 5 (2017) 325-360.

[7] K.C. Song, J.K. Park, H.U. Kang, S.H. Kim, Synthesis of hydrophilic coating solution for polymer substrate using glycidoxypropyltrimethoxysilane, J. Sol-Gel Sci. Technol. 27 (2003) 53-59.

[8] Y. Asthana, L.-Y. Hong, D.-P. Kim, T.S. Lee, Y.-M. Sung, Formulation of thermally cured organic-inorganic superhydrophilic coating for antifogging optical application, Mol. Cryst. Liq. Cryst. 463 (2007) (117/[399]-129/[411).
[9] M. Cullen, M. Morshed, M.O. Sullivan, E. Machugh, B. Duffy, M. Oubaha, Correlation Between the Structure and the Anticorrosion Barrier Properties of Hybrid Sol-Gel Coatings: Application to the Protection of AA2024-T3 Alloys, 82 (2017), pp. 801-816.

[10] B.A. Morrow, A.J. Mcfarlan, Surface vibrational modes of Sllanol groups on silica, J. Phys. Chem. 96 (1992) 1395-1400.

[11] D.M. Pickup, G. Mountjoy, G.W. Wallidge, R.J. Newporta, M.E. Smith, Structure of $\left(\mathrm{ZrO}_{2}\right)_{\mathrm{x}}\left(\mathrm{SiO}_{2}\right)_{1-\mathrm{x}}$ xerogels (x-0.1,0.2,0.3 and 0.4) FTIR, ${ }^{29} \mathrm{Si}$ and ${ }^{17} \mathrm{O}$ MAS NMR and EXAFS, Phys. Chem. Chem. Phys. 1 (1999) 2527-2533.

[12] M.R. Elvira, M.A. Mazo, A. Tamayo, F. Rubio, J. Rubio, J.L. Oteo, Study and characterization of organically modified silica-zirconia anti-graffiti coatings obtained by sol-gel, J. Chem. Chem. Eng. 7 (2013) 120-131.

[13] M. Handke, M. Kwaśny, Infrared spectroscopic study of octahydridooctasilsesquioxane hydrolytic polycondensation, Vib. Spectrosc. 74 (2014) 127-131.

[14] Ahmed Mahi, M. Belbachir, Abdelkadar. Ammari, R. Meghaber, M.I. Ferrahi, Synthesis and characterization of poly( $\mathrm{N}$-phenyl succinimide -thiopene) conducting polymer catalyzed by Maghnite H+, J. Electroanal. Chem. 823 (2018) 92-97.

[15] A. Belhocine, A. Haouzi, Ammari. Abdelkadar, Y. Chaker, G. Bassou, On the effect of benezethionium intercalation process; structural and dielectric properties of exchanged monotmorillonite, Colloid. Surf. A Physicochem. Eng. Asp. 577 (2019) 224-230.

[16] L. Lerot, P.F. Low, Effect of swelling on the infrared absorption spectrum of montmorillonite, Clay Clay Miner. 24 (1976) 191-199.

[17] K. Aboulkacem, A. Abdelkader, B. Bediaf, B. Amar, K. Abdelmalek, B. Hadj, Thermally activated charge transport in modified tetragonal zirconia thin films prepared by sol-gel method, Jpn. J. Appl. Phys. 57 (2018). 